\title{
Energy savings opportunities in the global digital television transition
}

\author{
Won Young Park (D) Anand Gopal • Amol Phadke
}

Received: 9 March 2016 / Accepted: 1 December 2016 /Published online: 20 December 2016

(C) The Author(s) 2016. This article is published with open access at Springerlink.com

\begin{abstract}
Globally, terrestrial television (TV) broadcasting is in the midst of a complete transition to digital signals. The last analog terrestrial broadcast is expected to be switched off in the early 2020s. This transition presents huge energy savings opportunities that have thus far been ignored. Digital TV switchovers have likely increased energy consumption as countries have completed transitions by providing digital TV converters to analog TV users, which increase energy consumption and extend the life of energy-inefficient ana$\log$ TVs. We find that if analog TVs were retired at the time of a digital switchover and replaced with superefficient flat-panel TVs, such as light-emitting diode (LED) backlit liquid crystal display (LCD) TVs, there is a combined electricity savings potential of 32 terawatt hours [TWh] per year in countries that have not yet completed their digital TV transition. In view of these findings as well as the dramatic drops of super-efficient TV prices and the unique early-retirement opportunity resulting from cessation of terrestrial analog broadcasts, TV-exchange programs would easily and substantially advance energy efficiency.
\end{abstract}

Keywords Digital television transition · Analog switch off · TV energy efficiency $\cdot$ Market transformation $\cdot$ LED backlit LCD TVs

W. Y. Park $(\bowtie) \cdot$ A. Gopal $\cdot$ A. Phadke

Energy Analysis and Environmental Impacts Division, Lawrence Berkeley National Laboratory, Berkeley, CA, USA e-mail: wypark@lbl.gov

\section{Introduction}

Since terrestrial digital television (TV) transitions began in 2003, many countries have completed the switchover, and many more are in the process of shifting from analog to digital TV (DTV) broadcasts (Burgess 2009, DVB 2015, ITU 2015). Countries are switching to DTV broadcasts for the following primary reasons (Kruger and Moore 2005):

- Over-the-air digital broadcasts will have much improved picture and sound quality compared to ana$\log$ broadcasts.

- A substantial amount of radio-frequency bandwidth will be freed up for other uses.

- The change will enable the delivery of over-the-air internet through TVs.

With the notable exception of Mexico, none of the countries that have completed or are in the process of DTV switchovers have seriously considered the energy savings opportunities presented by the transition. Instead, most countries have helped citizens with the digital transition by providing DTV converters (DTCs) that increase overall TV energy consumption. At the same time, the energy efficiency of flat-panel TVs has improved substantially in recent years, and their prices have dropped. When these trends are viewed in conjunction with the unique opportunity that the analog-to-DTV transition presents for early retirement of analog TVs, we find tremendous energy savings opportunities. Mexico is the first country to explicitly recognize 
this opportunity and is designing its DTV transition to include energy-efficiency goals. As part of the DTV transition, the Mexican government exchanges old analog TVs for flat-panel TVs that receive digital signals (Gopal et al. 2014, SEAD 2015). In this paper, we quantify the global energy savings potential of energy-efficiency opportunities available in upcoming DTV transitions, for example, through TV-exchange programs such as the one being implemented in Mexico.

Many countries have set timelines for ending analog terrestrial transmissions, with a vast majority expecting to complete the transition to digital broadcasts before 2020 (DVB 2015, Hai and Narayan 2012). Today, more than 300 million households still receive analog terrestrial TV signals (Murray 2014). This population represents a substantial energy savings potential. There have been some technical assessments of energy-efficiency improvement opportunities in DTCs (MVV 2007, TTA 2011, Cheung et al. 2011). However, to the authors' knowledge, no literature assesses the energy savings potential of DTV transitions if they are designed to take advantage of the energy-efficiency improvements offered by contemporary flat-panel TVs. Because flat-panel TV and DTC technology are very similar in all countries, we are able to do a global analysis of this potential.

In this paper, we estimate the energy use that would result from exchanging old analog TVs, all of which are cathode-ray tube (CRT) TVs, for light-emitting diode (LED) backlit liquid crystal (LCD) TVs (LED-LCD TVs). We compare that energy use with what would result from adding DTCs to extend the life of analog TVs after the digital switchover. Our analysis focuses on the countries where the numbers of analog TV households are still significant.

The remainder of this paper is organized as follows: "The global digital transition in broadcasting and televisions" section presents an overview of the digital broadcasting transition taking place across the globe and discusses energy consumption of DTCs and LCD TVs. "Methods, data, and scenarios" section describes our data sources, assumptions, and the methodology used to estimate energy savings potential in analog terrestrial TV households. "Results" section discusses our analysis results, and "Conclusions and policy implications" section presents concluding statements.

\section{The global digital transition in broadcasting and televisions}

Digital broadcasting platforms and global TV shipments

Digital terrestrial television (DTT) broadcasts have been growing, accounting for about $20 \%$ of the 1 billion DTV households worldwide in 2014 (Murray 2014). Of digital-broadcast recipient households (henceforth referred to as digital households), 36\% are cable TV subscribers who may own an analog TV but use a digital cable box from the service provider (Murray 2014, Cheung et al. 2011). Internet protocol and satellite (i.e., direct-to-home or DTH) make up the remaining $44 \%$ of digital households. As a result of the growing penetration of DTV broadcasts, the number of analog-broadcast recipient households (henceforth referred to as analog households), including terrestrial and cable, has been rapidly decreasing, from approximately 860 million households ( $\sim 60 \%$ of TV households) in 2010 to approximately 500 million households ( $\sim 32 \%$ of TV households) in 2014. Among those, analog terrestrial households number about 317 million in 2014 (Murray 2014). Because many countries have yet to complete a digital switchover, the energy savings opportunities in the global DTV transition could be substantial. There are four main DTT standards: ATSC (Advanced Television Systems Committee, adopted by USA, Canada, South Korea, Mexico, and some Central American countries); DVB-T (Digital Video Broadcasting-Terrestrial, adopted by Australia, Europe, Africa); ISDB-T (Integrated Services Digital Broadcasting-Terrestrial, adopted by Japan, Brazil, and several Latin American countries); DMB-T (Digital Terrestrial Multimedia Broadcast-Terrestrial, adopted by China) (ITU 2013, Pizzi and Jones 2014). More technical details of the four DTT standards are out of the scope of this paper.

Prior to 2007, sales of TVs that had a built-in digital tuner capable of directly receiving digital signals were not significant. We roughly estimate that less than 100 million flat-panel TVs were shipped between 1998 and 2006; by contrast, about 90 million flat-panel TVs were shipped in the year 2007 alone (DisplaySearch 2010). The cumulative global flat-panel DTV (TVs assumed to be mostly with built-in digital tuner and decoder) shipments 
between 2007 and 2014 were estimated to be approximately 1.4 billion units (DisplaySearch 2010, 2011, 2013, 2014a, 2014b). Given the significant number of DTV sales since 2007 and a TV lifetime of 6 years based on recent country-specific surveys (DisplaySearch 2012a), we estimate that roughly 1.2 billion digital flat-panel TVs (i.e., all high-definition [HD] or higher-definition flat-panel TVs) were in use worldwide in 2014. When we compare (see Fig. 1) this estimate with the number of digital households in 2014 ( $\sim 1$ billion) and account for digital household TV ownership rates $(>1)$, we can reasonably conclude that very few households that currently receive analog signals have already upgraded to digital TVs. We used this approach to estimate the number because we could not find data that directly report the TV type in analog households.

Penetration of digital broadcasts by country

The DTV transition is expected to accelerate as many countries have already set deadlines for digital switchover before 2020. According to Murray (2014), DTV broadcasts overall were estimated to have reached two thirds ( $\sim$ billion) of all TV households across 138 countries at the end of 2014. Top 10 countries (China, USA, India, Japan, Brazil, Germany, Russia, France, UK, and Italy) account for about $68 \%$ of the global digital households. The developed countries (USA, Japan, Germany, France, UK, and Italy) in the top 10 show high penetration rates of DTV households, in the range of 82 and $100 \%$; other countries have less than $60 \%$ penetration. Although it is not surprising that China has the largest number of TV and DTV households, it is also estimated that about 240 million households in China, India, and Indonesia were still receiving analog TV signals in 2014, accounting for $48 \%$ of total analog households worldwide. In China and Indonesia, about 78 and $100 \%$ of analog TV households, respectively, are estimated to receive analog terrestrial signals. Nearly $90 \%$ of ana$\log$ TV households in India are analog cable subscribers (Murray 2014). Countries in the AsiaPacific region, including China, India, and Indonesia, represent approximately $60 \%$ of global analog terrestrial TV households Fig. 2.

Digital TV technologies and related energy consumption trends

The United States Environmental Protection Agency (US EPA) ENERGY STAR program defines a DTC as "a device that receives terrestrial (over-the-air) digital signals and converts them to an analog output suitable for analog TVs". The definition does not include converters for satellite or cable digital signals or devices that perform multiple functions, e.g., DVD players with DTC capability (US EPA 2012). A settop box (STB) can be defined as "an appliance for the reception, decoding, processing and local networking of digital broadcasting and related services" (MVV 2007). As recent TVs have integrated tuners and decoders to receive digital broadcast signals, consumers who have those TVs do not need a basic DTC, which only converts digital broadcast signals into analog signals. Those households may want to
Fig. 1 Estimated numbers of global flat-panel TV shipments and digital TV households. Authors' work based on Murray (2014), DisplaySearch (2010, 2011, 2012a, 2013, 2014a, 2014b). Note: The figure does not include flat-panel TV shipments before 2007, which were negligible. TV shipments here refer only to flat-panel TVs with high definition (HD) or higher definition, e.g., full HD. The assumption of 6 years for TV economic lifetime is based on country-specific surveys (DisplaySearch, 2012a)

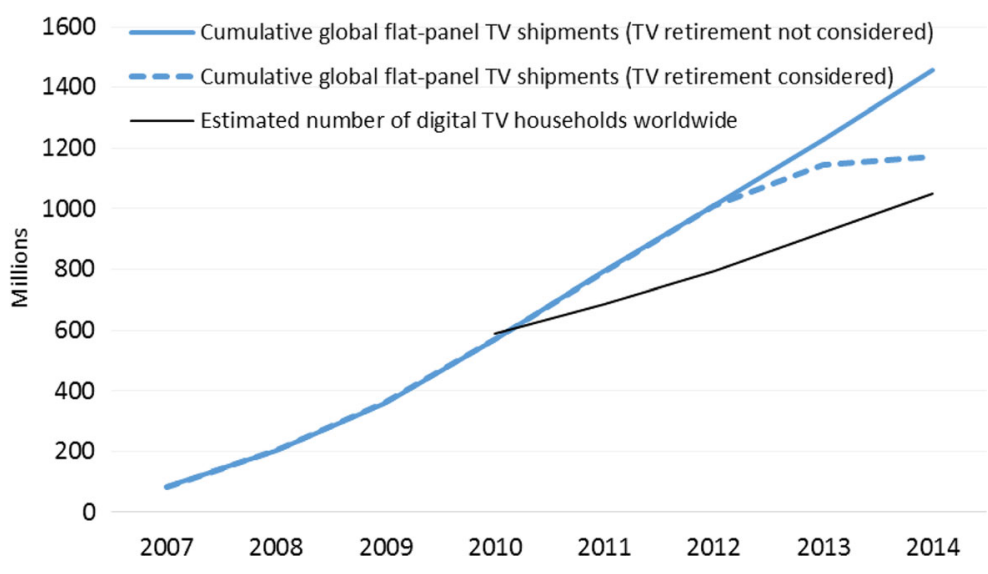


Fig. 2 Share of global digital and analog TV households in 2014. Authors' calculations based on Murray (2014)
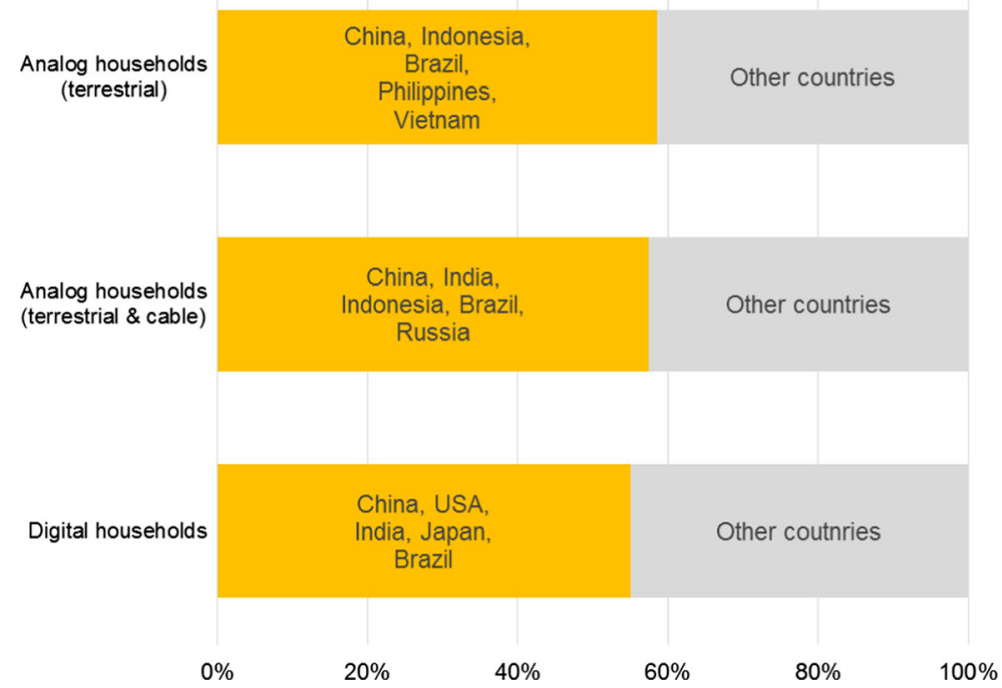

have a more complex and newer STB with additional features. However, households that are so far still using analog TVs (e.g., those in developing countries) will likely need a DTC to keep using their analog TVs after the digital switchover in their countries.

In the USA, the Federal Communications Commission (FCC) mandated that all US-based TV signals must be transmitted in a digital format starting in June 2009, but cable companies were not required to make the change (FCC 2009). In 2007, the US ENERGY STAR program required that the power consumption of DTCs not exceed 8 Watts [W] in "on" mode and $1 \mathrm{~W}$ in "sleep" mode and to incorporate an automatic power-down feature to switch from on to sleep mode after a period of time ( $4 \mathrm{~h}$ or less) without user input (US EPA 2007). According to Cheung et al. (2011), selected ENERGY STAR-qualified and nonENERGY STAR-qualified DTCs available in 2009 consumed on average 5.4 and $7.6 \mathrm{~W}$ in on mode, respectively, with an overall average of 6.5 W. A research team from the Natural Resources Defense Council (NRDC) and Ecos in 2010 investigated the energy consumption of various STB types, including those with additional features. Depending on specifications, the onmode power consumption of the products was mostly in the range of 10 to $50 \mathrm{~W}$ although the most efficient HD digital video recorders (HDDVRs) consumed less than $10 \mathrm{~W}$ (NRDC 2011). According to NCTA (2014), US ENERGY STAR
Version 3-qualified HD-DVRs and non-DVR STBs consume 21 and $15 \mathrm{~W}$, respectively, and STB efficiency is expected to be further improved by $10-45 \%$ by 2017 in the USA.

For the European region in 2007, a basic STB that meets the Digital Video Broadcasting-Terrestrial (DVB-T) standard and has no hard disk (i.e., a "simple" STB) was measured to consume about 4-15 W in on mode, and an STB with hard disk consumed about 14-23 W in on mode (MVV 2007). It is important to note that standby-mode power management may save significant STB electricity consumption because evidence has been reported that a majority of consumers do not switch STBs off but instead either switch to standby using remote control or leave the STB in on mode (MVV 2007). Since 2012, simple STBs sold in Europe have been required to consume no more than $5 \mathrm{~W}$ in on mode and $0.5 \mathrm{~W}$ in standby mode, with allowances for additional features such as hard disks, second tuners, and HD signal decoding (European Commission 2009).

South Korea completed its analog broadcast switchoff at the end of 2012 and adopted the Advanced Television Systems Committee (ATSC) DTT standard. Testing of seven DTC products available in 2011 in Korea revealed power consumption ranging from 3.9 to $5.3 \mathrm{~W}$ in on mode and 0.4 to $1.2 \mathrm{~W}$ in standby mode (TTA 2011). In China, GB 25958-2010, the energy efficiency standards for DTCs, requires that the power consumption of DTCs without additional functionality not 
exceed 5,7 , and $10 \mathrm{~W}$ in on mode and 1,2 , and $3 \mathrm{~W}$ in standby mode for Grade 1, 2, and 3, respectively (top10.cn 2014a). Energy-efficient DTC products selected by Top 10 China (http://www.top10.cn/) in 2014 showed power consumption ranging from 3 to $5 \mathrm{~W}$ in on mode and 0.3 to $1.0 \mathrm{~W}$ in standby mode (top $10 . \mathrm{cn} 2014$ b).

Although DTCs that primarily convert digital signals to analog signals are estimated to consume less than $10 \mathrm{~W}$ in on mode, DTCs or STBs with additional features such as recording require more energy. For example, the additional power consumption of hard disk and HD output with DTCs in China is required not to exceed 2.2 and $3.0 \mathrm{~W}$, respectively, for Grade 1 (top10.cn 2014a). Therefore, we conclude that the combination of an analog TV and a DTC (or STB) would consume substantially more energy than a typical 20- and 21-inch analog TV alone given that CRT TVs consume between 60 and $90 \mathrm{~W}$ in on mode (ECCJ 2010, Park et al. 2011).

Along with the DTV transition, TV screen technology has, in less than a decade, undergone a large-scale global market transition from CRT TVs to flat-panel TVs (Park et al. 2011, 2013, and 2014). LCD TVs were estimated to account for more than $95 \%$ of new TV shipments in 2014 and LED-LCD TVs to represent nearly $100 \%$ of total LCD TV shipments (DisplaySearch 2014c, IC Insights, n.d.). The rapid improvement in cost and efficacy of LED technologies has driven the adoption of LED backlights for LCD TVs and other applications. In addition to better LED performance, viable options to improve LCD TV efficiency include optimized combinations of optical films in LCDs and improved LCD panel transmittance, brightness control functions, and energyefficient power electronics (Park et al. 2011, 2013, 2014). In particular, major TV manufacturers have been providing new types of LED-LCD TVs at lower market prices to decrease the price gap between conventional LCD TVs and LED-LCD TVs. Manufacturers have achieved price reductions by decreasing the maximum luminance level, adjusting color reproduction capability, and redesigning the LED backlight structure (Park et al. 2014).

Although market prices for similar TV models produced by the same manufacturer vary by region, energy consumption remains largely the same. For example, the regional award-winning models of Samsung and LG in the Super-efficient Equipment and Appliance Deployment (SEAD) Global Efficiency Medal competition showed similar on-mode power consumption (see Table 1).

Although the global manufacturers (Samsung, LG, Sony, Panasonic, Sharp, and Toshiba) account for more than $60 \%$ of global TV sales, China, which has the single largest TV market (more than $20 \%$ of the global TV market), has been dominated by Chinese manufacturers that represent more than $70 \%$ of China's TV sales (DisplaySearch 2011, Park et al. 2011, 2013). It is difficult to obtain TV power consumption data measured by the same test method for all countries, but the highly globalized nature of TV manufacturing means that data available from the USA, China, and developing countries are useful.

Based on US ENERGY STAR-qualified LED-LCD TVs (84 models), recent 23-/24-inch (16:9 aspect ratio) LCD TVs consume 16 to $28 \mathrm{~W}$ regardless of backlight technology (US EPA 2015a). On-mode power consumption of the ENERGY STAR Most Efficient LED-LCD TVs (18 models, 15-24 in. on diagonal) in early 2015 ranged from 0.06 to $0.11 \mathrm{~W}$ per square inch [W/in ${ }^{2}$ ] (estimated to correspond to approximately 14 to $25 \mathrm{~W}$ for a 23-inch TV) (US EPA 2015b). The energy-efficient 32-inch TVs ( 8 models) selected by Top 10 China (http://www.top10.cn/) in 2015 consumed 28 to $52 \mathrm{~W}$ in on mode (equivalent to 0.06 to $0.12 \mathrm{~W} / \mathrm{in}^{2}$ estimated to correspond to 14 to $27 \mathrm{~W}$ for a 23 -inch TV).

The Global LEAP Outstanding Off-Grid TV Awards tested a number of direct current (DC) TVs designed for off-grid use to identify the world's highest-quality and most energy-efficient and affordable off-grid TVs. The DC TVs tested were 1523 in. on diagonal and had on-mode power consumption ranging from 0.05 to $0.10 \mathrm{~W} / \mathrm{in}^{2}$ (Global LEAP 2014) Table 2.

Although the product groups might not be entirely comparable (specifications such as network features, luminance default mode could be different), these models represent highly efficient TVs available in the USA, China, and developing countries. We can reasonably conclude from these data that on-mode power consumption of energyefficient LED-LCD TVs is similar across regions.

Typical 20-/21-inch (4:3 aspect ratio) CRT TVs are estimated to consume 60-90 W per unit (ECCJ 2010, 
Table 1 Award-winning models of the SEAD Global Efficiency Medal for TVs (2012)

\begin{tabular}{|c|c|c|c|c|}
\hline Region & Australia & Europe & India & North America \\
\hline Brand & Samsung & Samsung & Samsung & Samsung \\
\hline Model & UA26EH4000M & UE26EH4000W & UA26EH4000R & UN26EH4000F \\
\hline Nominal screen size (diagonal) & 26 in. & 26 in. & 26 in. & 26 in. \\
\hline On-mode power consumption & $24.4 \mathrm{~W}$ & $24.9 \mathrm{~W}$ & $24.9 \mathrm{~W}$ & $22.0 \mathrm{~W}$ \\
\hline Brand & Samsung & Samsung & Samsung & Samsung \\
\hline Model & UA40EH5306H & UE40EH5000W & UE40EH5330R & UE40EH5000F \\
\hline Nominal screen size (diagonal) & 40 in. & $40 \mathrm{in.}$ & $40 \mathrm{in.}$ & 40 in. \\
\hline On-mode power consumption & $47.4 \mathrm{~W}$ & $44.1 \mathrm{~W}$ & $47.4 \mathrm{~W}$ & $44.1 \mathrm{~W}$ \\
\hline Brand & LG & LG & LG & LG \\
\hline Model & 47LM6700 & LM670S & 47LM6700 & 47LM6700 \\
\hline Nominal screen size (diagonal) & 47 in. & 47 in. & $47 \mathrm{in.}$ & 47 in. \\
\hline On-mode power consumption & $43.4 \mathrm{~W}$ & $43.1 \mathrm{~W}$ & $43.4 \mathrm{~W}$ & $44.5 \mathrm{~W}$ \\
\hline
\end{tabular}

Source: Park (2013)

Park et al. 2011). Although replacing analog TVs with recent flat-panel TVs is more expensive than adding a basic STB or DTC to analog TVs, using energy-efficient flatpanel TVs will significantly reduce energy consumption and provide consumers with much better picture quality.

\section{Methods, data, and scenarios}

In this analysis, we estimate the global energy savings potential of replacing CRT TVs with LED-LCD TVs instead of connecting a DTC to the CRT TV to provide continued TV access after a digital switchover. We focus our analysis on analog terrestrial households because they will go dark during digital switchover. We exclude analog cable households that will be unaffected by a switchover. The estimated annual savings potential is based on all analog terrestrial stock (317 million households) being replaced by LED-LCD TVs, and the savings would be realized after the replacement has happened.

We break out our results for each of the top 10 countries (China, Indonesia, Brazil, Philippines, Vietnam, Bangladesh, Russia, Egypt, India, and Colombia) that represent about $70 \%$ of all analog terrestrial TV households (Murray 2014).

Table 2 On-mode power consumption of energy efficient TVs by region

\begin{tabular}{lllll}
\hline Region & USA & USA & China & Developing countries \\
\hline Data source & ENERGY STAR Most efficient & ENERGY STAR & Top 10 China & Global LEAP Awards ${ }^{\mathrm{a}}$ \\
Year & 2015 & 2015 & 2015 & $2013-2014$ \\
Screen size (diagonal, inches) & $15-24$ & $23-24$ & 32 & $15-23$ \\
$\begin{array}{l}\text { On-mode power performance (W/in } \\
\text { 2) }\end{array}$ & $0.06-0.11$ & $0.07-0.11$ & $0.06-0.12$ & $0.05-0.10$ \\
$\begin{array}{l}\text { Power consumption }(\mathrm{W}) \text { estimated } \\
\quad \text { for a 23-inch TV }\end{array}$ & $14-25$ & $16-25$ & $14-27$ & $11-23$ \\
\hline
\end{tabular}

${ }^{\text {a }}$ Global LEAP Award nominees were required to provide a brief written explanation, in English, of how the product warranty is serviced in two of the following six countries: Bangladesh, India, Indonesia, Kenya, Nigeria, and Uganda. The tested TVs are DC LED-LCD TVS, which are generally more efficient than AC LED-LCD TVs. The AC-to-DC conversion in the TV system typically results in an estimated 3$15 \%$ electricity loss

${ }^{\mathrm{b}}$ Authors' calculation

Source: US EPA (2015a), US EPA (2015b), Top 10 China (2015), Global LEAP (2014) 
Table 3 Average CRT TV screen size assumed in this analysis

\begin{tabular}{lll}
\hline Country & $\begin{array}{l}\text { Average size } \\
\text { (inches) }\end{array}$ & Notes \\
\hline China & 23.1 & Average of 2007-2011 CRT TVs shipped to China \\
India & 19.4 & Average of 2010-2012 CRT TVs shipped to India \\
Bangladesh, Indonesia, Philippines, Vietnam & 20.5 & Average of 2007-2011 CRT TVs shipped to Asia Pacific \\
Brazil & 20.9 & Average of 2007-2011 CRT TVs shipped to Latin America \\
Russia & 21.3 & Average of 2007-2011 CRT TVs shipped to Eastern Europe \\
Egypt, Colombia & 20.7 & Average of 2007-2011 CRT TVs shipped to Middle East and Africa \\
Rest of world & 21.2 & Average of 2007-2011 CRT TVs shipped globally
\end{tabular}

\footnotetext{
a Authors' estimates based on DisplaySearch (2010, 2011, 2012b)

b "Rest of world" includes 87 countries for analog terrestrial TV households. Among 138 countries included in Murray (2014), 41 are estimated to have no analog terrestrial TV households in 2014
}

Data and assumptions

\section{Average CRT TV screen size}

Average CRT TV screen sizes vary by region. In this analysis, we assume that the average CRT TV screen size is between 19 and 23 in., as summarized in Table 3.

\section{CRT TV on-mode power consumption}

According to a data set for TVs in Japan, 20-/21inch CRT TVs consume about $60-90 \mathrm{~W}$ in on mode (ECCJ 2010). However, these data were not measured by the IEC 62087 standard. Park et al. (2011) estimated the average per-unit on-mode power consumption of 21-inch CRT TVs on the global TV market to be about $60 \mathrm{~W}$. Phadke et al. (2015) estimated per-unit on-mode power consumption of 19-inch CRT TVs in developing countries to be about $60 \mathrm{~W}$. Efficiency of CRT TVs depends on the TV's vintage (year of manufacture). In this analysis, we assume that CRT TVs consume, on average, $0.33 \mathrm{~W} / \mathrm{in}^{2}$ in on mode, based on a range of 0.28 to $0.38 \mathrm{~W} / \mathrm{in}^{2}$, which is equivalent to about 60 $80 \mathrm{~W}$ for 21-inch CRT TVs.

\section{LED backlit LCD TV on-mode power consumption}

As discussed in "Digital TV technologies and related energy consumption trends" section, it is reasonable to assume that on-mode power consumption of energy-efficient LED-LCD TVs is similar across regions. Manufacturers will be able to adopt higher-efficacy LEDs and efficient LCD panels over time, but efficient optical films (e.g., reflective polarizers) and brightness control functions are already commercially available and have been used in selected models. These features reduce LED-LCD TV on-mode power consumption by about $40 \%$ (Park et al. 2013, 2014). The data from Table 2 represent energy-efficient TVs. We consider a wider (than shown in the table) range of TV power consumption and assume in this analysis that LED-LCD TVs available globally consume, on average, $0.10 \mathrm{~W} / \mathrm{in}^{2}$ in on mode, from a range of 0.06 to $0.14 \mathrm{~W} / \mathrm{in}^{2}$, equivalent to 11 to $26 \mathrm{~W}$ for 21 -inch TVs (Park et al. 2013, 2014).

\section{DTC power consumption}

As discussed in "The global digital transition in broadcasting and televisions" section, recent DTCs with primary function only (for standards ATSC and DVB-T) are estimated to consume at least $5 \mathrm{~W}$ in on mode and less than $1 \mathrm{~W}$ in standby (or sleep) mode. It is technically feasible for DTCs for ISDB-T and DVB-T2 to consume about $5 \mathrm{~W}$ using similar system-on-chip. However, DTCs' power consumption may also depend on region-specific requirements; for example, DVB-T2 specifications for Association of Southeast Asian Nations (ASEAN) countries require DTCs to be equipped with high-definition multimedia interface (HDMI) output and universal serial bus (USB) (ASEAN 2014). In this analysis, we assume that DTCs consume $6.5 \mathrm{~W}$ on average (from a range of 5 to $8 \mathrm{~W}$ ) in on mode and $0.5 \mathrm{~W}$ in standby mode. 
Table 4 Assumptions for TV and DTC power consumption and usage

\begin{tabular}{|c|c|c|c|c|}
\hline & & \multicolumn{3}{|c|}{ TV energy consumption assumptions } \\
\hline & & Low & Average & High \\
\hline CRT TV on mode & $\mathrm{W} / \mathrm{in}^{2}$ & 0.28 & 0.33 & 0.38 \\
\hline CRT TV standby mode & W & 1.00 & 1.00 & 1.00 \\
\hline LED-LCD TV on mode & $\mathrm{W} / \mathrm{in}^{2}$ & 0.06 & 0.10 & 0.14 \\
\hline LED-LCD TV standby mode & W & 0.50 & 0.50 & 0.50 \\
\hline DTC on mode & W & 5.00 & 6.50 & 8.00 \\
\hline DTC standby mode & W & 0.50 & 0.50 & 0.50 \\
\hline \multicolumn{5}{|l|}{ TV and DTC usage pattern assumptions } \\
\hline CRT TV and DTC usage on mode & hours/day & 3.5 & 4.0 & 5.0 \\
\hline DTC automatic power-down delay time & hours/day & 3.0 & 3.0 & 3.0 \\
\hline DTC average usage standby mode & hours/day & 17.5 & 17.0 & 16.0 \\
\hline LED-LCD TV usage on mode & hours/day & 3.5 & 4.0 & 5.0 \\
\hline LED-LCD TV usage standby mode & hours/day & 20.5 & 20.0 & 19.0 \\
\hline
\end{tabular}

\section{Average daily usage of TVs and DTCs}

We assume that every analog terrestrial household uses one TV unit. TV usage patterns vary by region, sector of use, and consumer lifestyle. Park et al. (2011) estimated average daily TV usage in various countries, which ranges from 3.5 to $6.5 \mathrm{~h}$. Usage averages in China, India, and Russia are 4, 3.5, and $4 \mathrm{~h}$, respectively. In South Korea and North American and European countries, average daily usage is more than $5 \mathrm{~h}$. In this analysis, we assume that average daily usage in on mode is $4 \mathrm{~h}$ for all TVs in the selected countries. We assume that DTCs are used for $4 \mathrm{~h}$ in on mode, are automatically switched to standby mode after $3 \mathrm{~h}$ of no activity (because consumers do not typically switch DTCs off immediately), and remain in standby mode for $17 \mathrm{~h}$. It is possible that daily TV usage will increase with adoption of DTV because of improved picture quality and lower energy costs. Therefore, for one of our scenarios, we assume $5 \mathrm{~h}$ per day in on mode for new digital TVs, which represents a substantial rebound effect.

\section{Uncertainties}

It is possible that a DTC's automatic power-down feature might not be enabled; in which case, the device would never switch to standby mode. It is also possible that some consumers will manually switch off DTCs at the end of each TV viewing session. Because these variations are subject to considerable uncertainty and it is difficult to quantify them, we do not attempt to account for them in our analysis. Another variable is that households with DTCs might also purchase LED-LCD TVs earlier than expected, so we cannot be certain of the number of years during which our annual estimated savings might apply.

Table 4 summarizes our assumptions for TV and DTC power consumption and usage.

Table 5 Scenarios for estimating electricity savings potential

\begin{tabular}{llll}
\hline & \multicolumn{2}{l}{ Scenarios } & \\
\cline { 2 - 4 } & Minimum savings & Average savings & Maximum savings \\
\hline CRT TV and DTC on-mode power & Low & Average & High \\
CRT TV and DTC daily usage & Average & Average & Average \\
LED-LCD TV on-mode power & High & Average & Low \\
LED-LCD TV daily usage & High (rebound) & Average & Average (no rebound) \\
\hline
\end{tabular}

See Table 4 for detailed assumptions 
Fig. 3 Estimated global annual TV electricity consumption of analog terrestrial TV households. The other 7 of the top 10 countries are the Philippines, Vietnam, Bangladesh, Russia, Egypt, India, and Colombia

-China $\square$ Indonesia $\square$ Brazil $\square$ the other 7 out of top 10 countries $\boxminus$ Rest of World

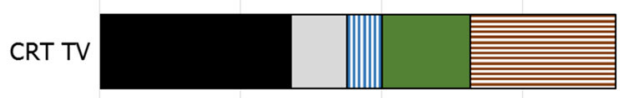

CRT TV + DTC

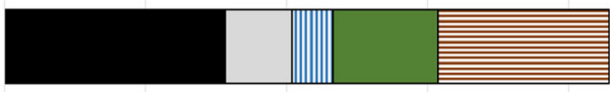

Standard LED-LCD TV

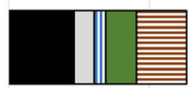

0

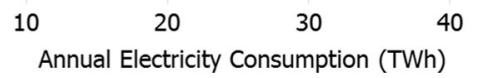

Estimating annual electricity savings potential by scenario

We estimate the annual energy savings potential for three scenarios. In each scenario, the savings potential is estimated by subtracting the total annual electricity consumption in the efficiency case(s) with LED-LCD TVs from the total annual electricity consumption in the base case with CRTs and DTCs. However, we do not know the vintage of CRT TVs in analog households and therefore cannot be certain of those TVs' energy efficiency. Thus, it is useful to consider minimum, average, and high savings cases for TV and DTC power consumption and usage. In the minimum savings scenario, we assume a high energy efficiency for CRTs and DTCs and a low energy efficiency for LED-LCD TVs, including a rebound effect of one additional hour of daily viewing. In the average savings scenario, we compare a CRT and DTC of average efficiency with standard LED-LCD TVs. In the maximum savings scenario, we compare an inefficient CRT and DTC with a superefficient LED-LCD TV, assuming no rebound effect. Table 5 summarizes these scenarios.

In addition to the three scenarios above, which reflect possible combinations of parameters, we conduct additional sensitivity analyses for selected parameters:

- Average savings scenario and CRT TV on-mode power (Low/High)

- Average savings scenario and DTC on-mode power (Low/High)
Table 6 Estimated global annual TV electricity consumption of analog terrestrial households (average savings scenario)

\begin{tabular}{llll}
\hline Country & Base case (A) & Efficiency case (B) & Savings (B-A) \\
\hline China & 15.6 & 3.8 & 11.8 \\
Indonesia & 4.7 & 1.1 & 3.6 \\
Brazil & 2.9 & 0.7 & 2.2 \\
Philippines & 1.4 & 0.3 & 1.1 \\
Vietnam & 1.1 & 0.3 & 0.9 \\
Bangladesh & 1.1 & 0.3 & 0.8 \\
Russia & 1.1 & 0.3 & 0.9 \\
Egypt & 1.0 & 0.2 & 0.7 \\
India & 0.8 & 0.2 & 0.6 \\
Colombia & 0.9 & 0.2 & 0.7 \\
Other (87 countries) & 12.1 & 2.9 & 9.2 \\
Total & 42.8 & 10.4 & 32.4 \\
\hline
\end{tabular}


Table 7 Estimated annual electricity consumption and savings by all scenarios

\begin{tabular}{|c|c|c|c|}
\hline & \multicolumn{3}{|l|}{ Scenarios } \\
\hline & Minimum savings & Average savings & Maximum savings \\
\hline CRT TV on-mode power $\left(\mathrm{W} / \mathrm{in}^{2}\right)$ & 0.28 & 0.33 & 0.38 \\
\hline DTC on-mode power $(\mathrm{W})$ & 5.00 & 6.50 & 8.00 \\
\hline CRT TV and DTC daily usage (hours/day) & 4.00 & 4.00 & 4.00 \\
\hline LED-LCD TV on-mode power (W/in²) & 0.14 & 0.10 & 0.06 \\
\hline LED-LCD TV daily usage (hours/day) & 5.00 & 4.00 & 4.00 \\
\hline Annual electricity consumption in CRTs & 31.40 & 36.60 & 41.80 \\
\hline Annual electricity consumption in CRTs and DTCs & 36.40 & 42.80 & 49.20 \\
\hline Annual electricity consumption in LED-LCD TVs & 17.30 & 10.40 & 6.70 \\
\hline Savings by (CRTs + DTCs) - (LED-LCD TVs) & 19.10 & 32.40 & 42.50 \\
\hline
\end{tabular}

Unit: TWh per year

- Average savings scenario and LED-LCD TV onmode power (Low/High)

- Average savings scenario and TV daily usage (Low/ High, no rebound)

\section{Results}

Based on the discussion and assumptions in the previous sections, this analysis compares future annual TV electricity consumption for three major scenarios.

Average savings potential scenario

The total annual CRT TV electricity consumption from all analog terrestrial TV households is estimated to be
36.6 terawatt hours $[\mathrm{TWh}]$ per year. The added consumption from DTCs after a digital switchover is estimated to be $6.2 \mathrm{TWh}$, resulting in total annual electricity consumption of $42.8 \mathrm{TWh}$ from CRTs after the digital switchover. The estimated global electricity consumption from LED-LCD TVs installed in formerly analog households is estimated to be $10.4 \mathrm{TWh}$ per year (standard efficiency). Thus, we estimate an average energy savings potential that varies from $32.4 \mathrm{TWh}$ per year Fig. 3.

Table 6 shows that the top three countries - China, Indonesia, and Brazil-together account for 54\% of total TV electricity savings potential. In China and Indonesia, about 78 and $100 \%$ of analog TV households, respectively, are estimated to receive analog terrestrial signals. Nearly $90 \%$ of analog TV households in India are analog cable subscribers (Murray 2014), so the
Fig. 4 Savings potential with selected parameters compared to average savings scenario. See Table 3 and Table 4 for detailed assumptions

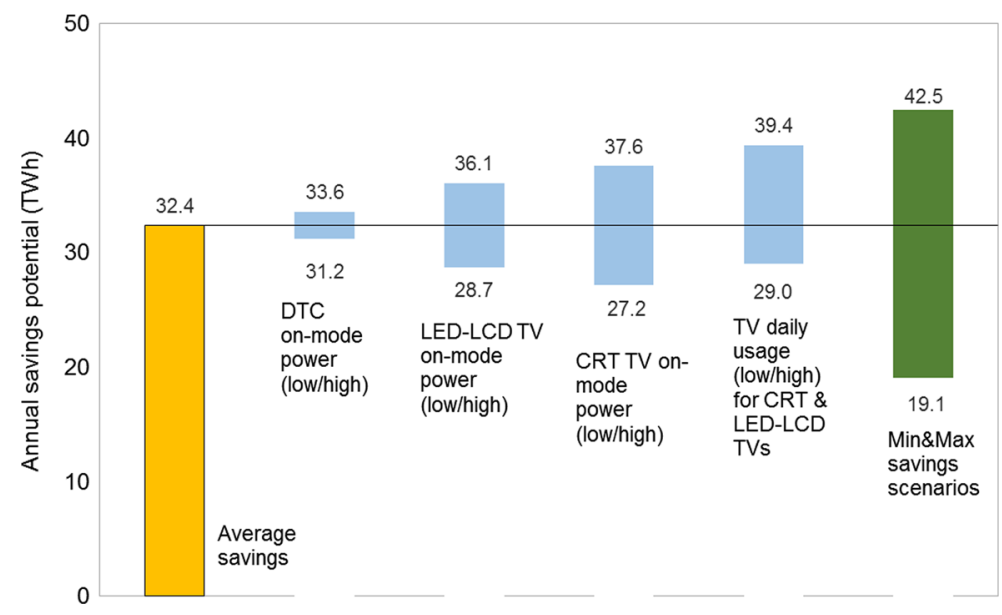


savings potential in India is small because analog cable households will be unaffected by the digital switchover.

All scenarios and sensitivity analysis

As discussed in "Estimating annual electricity savings potential by scenario" section, we developed the minimum and maximum savings scenarios because of uncertainties in our inputs and assumptions. The absolute lower-bound savings scenario still shows annual electricity savings of $19.1 \mathrm{TWh}$ per year. The upper-bound estimate is 42.5 TWh per year. Table 7 shows the details of the sensitivity scenarios.

Below, we present results of additional sensitivity analyses for selected parameters under the average savings scenario. These analyses account for possible variation in the factors that affect TV electricity consumption. More-efficient LED-LCD TVs, less-efficient existing CRT TVs, and increased viewer usage of TVs are expected to increase savings by $11-22 \%$ compared to the average savings scenario Fig. 4.

\section{Conclusion and policy implications}

Providing DTCs might seem to be an easy, economical way to respond to the switch to digital TV transmissions without replacing analog CRT TVs. However, CRT TVs consume more than three times as much electricity as recent LED-LCD TVs. Our analysis shows that if TV users are given DTCs to continue using their CRT TVs, electricity consumption will increase by 6.7 TWh per year globally.

LED-LCD TVs with on-mode power consumption of less than $0.10 \mathrm{~W} / \mathrm{in}^{2}$ (equivalent to about $23 \mathrm{~W}$ for a 23 inch TV with 16:9 aspect ratio) are widely available, and the efficiency of LED-LCD TVs can be further improved by adding technologies that are already commercial. Thus, we find enormous electricity savings potential from replacing analog CRT TVs with LED-LCD TVs as part of a switchover to digital technology. The estimated annual $32 \mathrm{TWh}$ savings potential in our average savings scenario is equivalent to about 11 Rosenfelds. ${ }^{1}$ Even when we consider possible variations

\footnotetext{
${ }^{1}$ One Rosenfeld unit is defined to be an average coal plant capacity of $500 \mathrm{MW}$ with a capacity factor of $70 \%$ and system-wide transmission and distribution losses of $7 \%$ or annual delivered electricity of about 3 TWh per year (Koomey et al. 2010).
}

and uncertainties in energy consumption, the estimated annual savings potential is in the range of 19 to $43 \mathrm{TWh}$ per year. Although the annual savings potential will decrease as consumers purchase new TVs at some point, this huge savings potential still indicates that total cumulative savings for several years would be much larger if policy action is made in a timely manner, given the long lifetime of TVs.

Given rapidly decreasing flat-panel TV prices and TVs' long lifetime, planning to incorporate energy-efficient TVs as part of digital transitions, rather than relying DTCs that extend the use of inefficient old analog TVs, is likely to be beneficial in reducing energy consumption in the short and long run. The energy savings that we estimate equate to substantial cost savings in each country from avoided power generation. Government procurement or incentive programs can significantly reduce the up-front cost of LED-LCD TVs. Several governments that are considering subsidizing the cost of DTCs or STBs for low-income households that have analog TVs could benefit from analyzing the potential impact on energy and financial savings of replacing analog TVs with energy-efficient models instead. Countries like Mexico that have been subsidizing residential electricity prices could further reduce the cost of supporting the digital switchover. For example, Gopal et al. (2014) highlighted that electricity subsidies lower the value of energy efficiency to the consumer and estimated the positive marginal savings for the Mexican government that could result from appliance efficiency, based on Mexico's tariff structures and the long-run marginal cost of supply. In Mexico, a TV-exchange program associated with the digital transition would not only save 3.5 TWh per year in electricity but would also save the government approximately $\$ 2.3$ billion in avoided electricity subsidy payments (SEAD 2015).

While our analysis does show enormous savings, the 317 million analog (terrestrial) TVs that need to be replaced to realize these savings represent a larger number than current annual global TV shipments. Thus, if countries plan to institute an exchange program such as that described above, they will need to engage with manufacturers to avoid supply-chain bottlenecks. Future research on energy efficiency in DTV transitions should discuss country-specific impacts on energy and cost savings of adoption of energy-efficient TVs, and 
appropriate policy and program design, given each country's appliance market and electricity price structure.

Acknowledgements This work was funded by the Bureau of Oceans and International Environmental and Scientific Affairs, US Department of State and administered by the US Department of Energy in support of the Super-efficient Equipment and Appliance Deployment (SEAD) Initiative through the US Department of Energy under Contract No. DE-AC02-05CH11231. Any errors or omissions are the authors' own.

Open Access This article is distributed under the terms of the Creative Commons Attribution 4.0 International License (http:// creativecommons.org/licenses/by/4.0/), which permits unrestricted use, distribution, and reproduction in any medium, provided you give appropriate credit to the original author(s) and the source, provide a link to the Creative Commons license, and indicate if changes were made.

\section{References}

Association of Southeast Asian Nations (ASEAN). (2014). DVBT2 Integrated receiver Decoder Technical Specification for ASEAN Version 1.0. June

Burgess, John. (2009). Throwing the Switch: Challenges in the Conversion to Digital Broadcasting: A report to the Center for International Media Assistance (CIMA). http://www. cima.ned.org/resource/throwing-the-switch-challenges-inthe-conversion-to-digital-broadcasting/

Cheung, H. Y., et al. (2011). Energy savings assessment for digital-toanalog converter boxes. Energy Policy, 39(2011), 1312-1317.

Digital Video Broadcasting Project (DVB). (2015). DTT Deployment Data. https://www.dvb.org/news/worldwide

DisplaySearch. (2010). Quarterly Advanced Global TV Shipment and Forecast Report. First Quarter

DisplaySearch. (2011). Quarterly Advanced Global TV Shipment and Forecast Report. Fourth Quarter

DisplaySearch. (2012a). Global TV Replacement Cycle Falls Below 7 Years, as Households continue to Replace Older CRT TVs and Upgrade to Larger Flat Panel Sets. http://www. displaysearch.com/cps/rde/xchg/displaysearch/hs. xsl/120529_global_tv_replacement_cycle_falls_below_7 years_as_households_continue_to_replace.asp

DisplaySearch. (2012b). Quarterly India TV Shipment and Forecast Database. Third Quarter.

DisplaySearch. (2013). Global LCD TV Shipments Fall for the First Time in 2012; Outlook Cautious for 2013. http://www. displaysearch.com/cps/rde/xchg/displaysearch/hs.xs1/130321 global_lcd_tv_shipments_fall_for_the_first time_in_2012.asp

DisplaySearch. (2014a) TV Panel Shipments Hit Record in 2013, But is it Too High? February. http://www.displaysearchblog. com/2014/02/tv-panel-shipments-hit-record-in-2013-but-isit-too-high/

DisplaySearch. (2014b). LCD TV Shipment Forecast Revised Upward on Strong Consumer Demand for Larger Sizes, D e c e mber. htt p:// www.dis plays e a r ch. com/cps/rde/xchg/displaysearch/hs.xsl/141231_lcd_tv_ shipment_forecast_revised_upward_on_strong_consumer demand_for_larger_sizes.asp

DisplaySearch. (2014c). LCD TV Growth Improving, As Plasma and CRT TV Disappear. April. http://www.displaysearch. com/cps/rde/xchg/displaysearch/hs.xsl/140415_lcd_tv growth_improving_as_plasma_and_crt_tv_disappear.asp

Energy Conservation Center, Japan (ECCJ). (2010). Catalog of efficient TVs in Japan

European Commission (EC). (2009). Commission Regulation (EC) No 107/2009 of 4 February 2009 implementing directive 2005/32/EC of the European Parliament and of the Council with regard to ecodesign requirements for simple set-top boxes. Office Journal of the European Union. http://eur-lex.europa.eu/legal-content/EN/TXT/PDF/?uri= CELEX:32009R0107\&from=EN

Federal Communications Commission (FCC). (2009). Digital Television. http://www.fcc.gov/digital-television

Global Lighting and Energy Access Partnership (Global LEAP). (2014). Global LEAP Outstanding Off-Grid Product Awards Results

Gopal, A., et al. (2014). Self-financed efficiency incentives: case study of Mexico. Energy Efficiency, 7, 865-877.

Hai, P. and Narayan, A. (2012). Trends in transition from analogue to digital broadcasting. Presented at the ITU-AIBD-ABU Workshop on Digital Broadcasting in Thailand

IC Insights. (n.d.). Global LCD-LED TV shipments forecast from 2009 to 2016 (in million units). In Statista - The Statistics Portal (Retrieved June 19, 2015). http://www.statista. com/statistics/260371/global-lcd-led-tv-shipments-forecast/

International Telecommunication Union (ITU). (2013). Measuring the Information Society 2013. ISBN 978 92-61-14401-2. http://www.itu.int/en/ITUD/Statistics/Documents/publications/mis2013/MIS2013 without_Annex_4.pdf

International Telecommunication Union (ITU). (2015). Status of the transition to Digital Terrestrial Television Broadcasting: Summary. http://www.itu.int/en/ITU-D/SpectrumBroadcasting/Pages/DSO/Summary.aspx

Koomey, J., et al. (2010). Defining a standard metric for electricity savings. Environmental Research Letters, 5, 014017.

Kruger, Lennard G. and Moore, Linda K. (2005). The Digital TV Transition: A Brief Overview. The Digital Report for Congress http://digital.1ibrary.unt.edu/ark:/67531 /metacrs7682/m1/1/high_res_d/RS22217_2005Aug12.pdf

Murray, Simon. (2014). Digital TV World Household Databook 2014 Edition. Digital TV Research Ltd

MVV Consulting GmbH. (2007). Simple Digital TV Converters (Simple Set Top Boxes) Final Report of Preparatory Studies for Eco-design Requirement of EuPs. Submitted to European Commission DG TREN. http://www.eup-network. de/fileadmin/user upload/Produktgruppen/Lots/Final Documents/Final_Report_Simple_STB_200108.pdf

National Cable \& Telecommunications Association (NCTA). (2014). Set-Top Box Energy Efficiency. https://www.ncta. com/sites/prod/files/NCTA_Set-TopBoxEnergyEfficiency.pdf

Natural Resources Defense Council (NRDC). (2011). Better Viewing, Lower Energy Bills, and Less Pollution: Improving the Efficiency of Television Set-Top Boxes. http://www.nrdc.org/energy/files/settopboxes.pdf 
Park, Won Young. (2013). Assessment of 2012 Global Energy Efficiency Medal for televisions. Lawrence Berkeley National Laboratory (LBNL). Super-efficient Equipment and Appliance Deployment (SEAD) Initiative. http://superefficient. org/Research/PublicationLibrary/2013/Assessment-of-SEADGlobal-Efficiency-Medals-for-Televisions

Park, Won Young. et al. (2011). TV Energy Consumption Trends and Energy-Efficiency Improvement Options. LBNL-5024E. Lawrence Berkeley National Laboratory. http://eetd.lbl.gov/publications/tv-energy-consumptiontrends-and-ener

Park, W. Y., et al. (2013). Efficiency improvement opportunities in TVs: implications for market transformation programs. Energy Policy, 59(2013), 361-372.

Park, W. Y., et al. (2014). Efficiency improvement opportunities for televisions in India: implications for market transformation programs. Energy Efficiency, 7, 811-832.

Phadke, Amol et al. (2015). Powering a Home with Just 25 Watts of Solar PV: Super-Efficient Appliances Can Enable Expanded Off-Grid Energy Service Using Small Solar Power Systems. LBNL-175726. Lawrence Berkeley National Laboratory. http://www.cleanenergyministerial. org/Portals/2/pdfs/GlobalLEAP-PoweringAHome.pdf

Pizzi, Skip. and Jones, Graham. (2014). A Broadcast Engineering Tutorial for Non-Engineers 4th Edition. National Association Broadcasters (NAB)

Super-efficient Equipment and Appliance Deployment (SEAD). (2015). Pursuing Energy Savings Opportunities in Mexico's Digital TV Transition. http://www.superefficient.org/About-
Us/News/Pursuing-Energy-Savings-Opportunities-inMexico-Digital-TV-Transition

Telecommunications Technology Association. (TTA). (2011). Establishment of Standby Power Reduction Criteria for Digital Convertor, and Cordless/Corded Phones and Door Phones Requirements Reinforcement

Top10.cn. (2014b). List of digital TV adapters selected by Top10 China. Updated on December 26, 2014.

Top10.cn. (2014a). Selection Criteria for Digital TV adapter. Updated on December 26, 2014. http://www.top10. $\mathrm{cn} /$ English/Selection-Criteria/Digital-TV-Adapter-SelectionCriteria-EN.html

United States Environmental Protection Agency (US EPA). (2007). ENERGY STAR® Program Requirements for Digital-to-Analog Converter Boxes (DTAs) Eligibility Criteria. https://www.energystar.gov/ia/partners/prod_ development/new_specs/downloads/DTA_Final_Spec. pdf?69cd-053f

United States Environmental Protection Agency (US EPA). (2012). ENERGY STAR® Program Requirements for Set-top Boxes Eligibility Criteria Version 3.0. Revision October 2012. http://www.energystar.gov/sites/default/files/specs//ES_STB_ Version_3_Program_Requirements_Manufacturer_ Oct2012_0.pdf

United States Environmental Protection Agency (US EPA). (2015a). List of ENERGY STAR qualified TVs. Access on Mar 5, 2015

United States Environmental Protection Agency (US EPA). (2015b). List of ENERGY STAR Most Efficient qualified TVs. Access on Mar 27, 2015. 